\title{
Influence of Extreme Temperature on the Pore and Fracture Development of High-Rank Coal
}

\author{
Ming Yang $\mathbb{D}^{1,2,3}$ and Jingcang $B i \mathbb{D}^{3}$ \\ ${ }^{1}$ The Collaborative Innovation Center of Coal Safety Production of Henan, Jiaozuo, Henan 454003, China \\ ${ }^{2}$ State Key Laboratory Cultivation Base for Gas Geology and Gas Control, Henan Polytechnic University, Jiaozuo, \\ Henan 454003, China \\ ${ }^{3}$ School of Safety Science and Engineering, Henan Polytechnic University, Jiaozuo, Henan 454003, China \\ Correspondence should be addressed to Ming Yang; Yming2005@163.com
}

Received 25 May 2018; Accepted 10 July 2018; Published 18 September 2018

Academic Editor: Guozhong Hu

Copyright (c) 2018 Ming Yang and Jingcang Bi. This is an open access article distributed under the Creative Commons Attribution License, which permits unrestricted use, distribution, and reproduction in any medium, provided the original work is properly cited.

\begin{abstract}
Pore and fracture structures in coals and their distribution features play an important role in the enrichment and osmosis migration of coalbed methane (CBM). The modification and antireflection of pore and fracture in coal reservoir through ultrahigh and ultralow temperature stress, such as liquid nitrogen frozen-induced cracking and thermal antireflection of coal reservoir, have attracted wide research attention. This study conducted a nuclear magnetic resonance (NMR) experiment of pore and fracture features of coal samples under two extreme temperatures $\left(100^{\circ} \mathrm{C},-196^{\circ} \mathrm{C}\right)$ using the Meso MR23-060H-I low-field NMR and imaging instrument. The influencing law of ultrahigh and ultralow temperature stress on pore and fracture development in highrank coal was discussed. Results demonstrated that temperature can influence pore and fracture development of high-rank coal samples. The pore volume, porosity, and permeability of the coal sample increase after low-temperature $\left(-196^{\circ} \mathrm{C}\right)$ treatment. The proportion of microspores decreases, the proportion of small pores increases, the proportion of mesopores remains the same, and the proportion of macrospores increases to some extent. The pore volume of coal sample decreases after high-temperature $\left(100^{\circ} \mathrm{C}\right)$ treatment. Porosity and permeability decrease. The proportion of mesopores declines, the proportion of mesopores remains basically same, and the proportion of macrospores decreases.
\end{abstract}

\section{Introduction}

Coal reservoirs are dual structural systems composed of pores and fractures. The pore-fracture system in a coal reservoir is the accumulation place and migration channel, respectively, of coalbed methane (CBM). The distribution and structural features of pores and fractures in coal reservoir affect the enrichment and osmosis migration of CBM [1]. Pore and fracture development and deformation in coal reservoirs are highly sensitive to axial pressure, confining pressure, temperature stress, and gas pressure $[2,3]$ because of the low strength and significant deformation amplitude of the porefracture system under effective stress. High-rank coal reservoir is characterized by high degree of metamorphism, strong anisotropism, matrix density, high adsorption capacity of coalbed, and poor permeability [4]; these characteristics result in the low gas extraction efficiency of CBM in high-rank coal reservoirs. Therefore, increasing the gas extraction efficiency of CBM by changing the permeability of high-rank coal reservoir is one of the key challenges in unconventional CBM extraction and gas disaster control in coal mines.

Chinese and foreign scholars conducted experimental studies on the sensitivity of pore and fracture development in coal or rocks to temperature stress. Wu et al. $[5,6]$ discussed the mechanical properties of sandstone, limestone, marble, and granite after high-temperature treatment. Qiu et al. [7] studied the effects of temperature on fracture density and the release rate of damage strain energy of granite. Yang $[8,9]$ analyzed the strength features of coal petrography and sandstone under the same confining pressure but different 
temperatures and under the same temperature but different confining pressures. He found that the strength growth of coal rock with reduced temperature is mainly attributed to the increased peak strength of water-rich frozen rocks due to mineral shrinkage, ice strength, and frost heaving of rocks. Feng et al. [10] studied the permeability characteristics of coal rock during anthracite deformation under temperature effects. $\mathrm{Hu}$ et al. [11] conducted an experiment on the effect of temperature on the permeability characteristics of lignite. Li [12] explored the changes of permeability characteristics and microstructure of lignite at pyrolysis. Yang and Zhang [13] conducted an experimental study of the influencing law of temperature on gas permeability in coals. These results comprehensively showed the variation characteristics of pores and fractures in coal body and the adsorptiondesorption law of gas in the temperature range of -$30^{\circ} \mathrm{C}$ to $80^{\circ} \mathrm{C}$. These studies also facilitated increased understanding of the relationship between pore and fracture characteristics in coal body and temperature stress.

Research on modified antireflection of pores and fractures in coal reservoir through temperature stresses (e.g., liquid nitrogen frozen-induced cracking technology and thermal antireflection of coal reservoir) have attracted wide attention. How do high temperature $\left(>100^{\circ} \mathrm{C}\right)$ and ultralow temperature (about $-200^{\circ} \mathrm{C}$ ) influence the pore and fracture development of coal body under new technological conditions? These problems require urgent and in-depth analysis. Thus, pore and fracture characteristics under ultrahigh and ultralow temperature stress were studied using low-field NMR. This approach aimed at disclosing the influence of ultrahigh and ultralow temperature stress on pore and fracture characteristics and providing theoretical references and guidance for the applications of coal modification, CBM extraction, and other relevant technologies under ultrahigh and ultralow temperature stress.

\section{Principle of Low-Field NMR Experiment}

NMR is a physical phenomenon that generates spectral signals through the interaction between spinning atomic nucleus with odd nucleus (e.g., ${ }^{1} \mathrm{H},{ }^{13} \mathrm{C},{ }^{19} \mathrm{~F}$, and ${ }^{31} \mathrm{P}$ ) and low-frequency electric wave [14]. Low-field NMR is used to test coal by low magnetic field intensity and detect the nuclear magnetic signal of ${ }^{1} \mathrm{H}$ in water-saturated coal rock pores to gain the transverse relaxation time $\left(T_{2}\right)$ spectrum of ${ }^{1} \mathrm{H}$ and the $T_{2}$ spectrum of water in water-saturated coal rock. This $T_{2}$ spectrum can be used to analyze the characteristics of pore diameter distribution and the connectivity and physical characteristics of coal samples [15].

Relaxation time refers to the duration of vector magnetization from the excited state to equilibrium. Relaxation can be divided into transverse $\left(T_{2}\right)$ and longitudinal $\left(T_{2}\right)$. The applications of NMR in coal rocks mainly focus on $\left(T_{2}\right)$ tests [16]. The relaxation mechanisms of $T_{2}$ include free relaxation, surface relaxation, and diffusion relaxation [17], which can be expressed as

$$
\frac{1}{T_{2}}=\frac{1}{T_{2 \mathrm{~F}}}+\frac{1}{T_{2 \mathrm{~S}}}+\frac{1}{T_{2 \mathrm{D}}},
$$

where $T_{2}$ means the transverse relaxation time of the porous fluid collected by Carr-Purcell-Meiboom-Gill (CPMG) sequence, $T_{2 \mathrm{~F}}$ is the free relaxation time, $T_{2 \mathrm{~S}}$ is the surface relaxation time, and $T_{2 \mathrm{D}}$ is the diffusion relaxation time.

$T_{2 \mathrm{~F}}$ and $T_{2 \mathrm{D}}$ are determined by the physical properties (e.g., chemical components and viscosity) of fluid. The experiments are generally performed in a uniform magnetic field. Thus, the influences of free and diffusion relaxations can be neglected. $T_{2 S}$ is the relaxation action of pore surface in coal rock on the fluids and is unrelated to the specific surface area of pores. $T_{2 S}$ also takes the dominant role in relaxation. Equation (1) can be simplified into

$$
\frac{1}{T_{2}} \approx \frac{1}{T_{2 S}}=\rho_{2} \times\left(\frac{S}{V}\right) \times P,
$$

where $\rho_{2}$ means the surface relaxation rate of coal samples and $(S / V) \times P$ is the specific surface area of pores. Suppose pore is a cylinder with a radius of $R$. Then, (2) can be further simplified as follows:

$$
\begin{aligned}
& T_{2}=F_{\mathrm{S}} \times R, \\
& F_{\mathrm{S}}=\frac{1}{2 \rho_{2}} .
\end{aligned}
$$

Equation (3) shows that $T_{2}$ distribution is related to pore size. The larger the pore size is, the higher the $T_{2}$ and the longer the water relaxation time in pores will be. By contrast, $T_{2}$ is smaller under smaller pore diameter, which is accompanied by stronger constraint to water in pores and shorter relaxation time. This finding shows that the position of relaxation peak and peak area size are related to pore diameter $[18,19]$. According to the literature review [20], the surface relaxation rate of high-rank coal core is $\rho_{2}=5.4 \mu \mathrm{m} / \mathrm{s}$. Therefore, the $T_{2}$ spectrum of coal samples can be converted into pore diameter distribution graph of coal samples.

Low-field NMR measures porosity in the core and extracts core sample into vacuum followed by water saturation to fill the pores in the sample with water. Thus, the pore volume of samples is equal to water yield. Water yield could be measured by NMR. High porosity contributes high water yield and strong nuclear magnetic signals. Samples (generally 3-6) with certain volume and known porosity will first gain the relation curve between NMR signal strength and porosity (spectrum sample curve). Next, samples with unknown porosity were measured by this spectrum sample curve to facilitate calculation of the porosity of samples [21, 22].

NMR permeability calculation used the Coates model [23]. Pore size parameters are used in an implicit manner through the cutoff value of $T_{2}$. These parameters determine the ratio between free fluid index (FFI) and bound fluid index (BVI).

The expression of permeability $(K)$ in the Coates model is given as 
TABLE 1: The basic parameters and proximate analysis results of coal samples.

\begin{tabular}{lcccccccc}
\hline Sample & $\begin{array}{c}\text { Original } \\
\text { quality } m_{1}(\mathrm{~g})\end{array}$ & $\begin{array}{c}\text { Saturated water } \\
\text { quality } m_{2}(\mathrm{~g})\end{array}$ & $\begin{array}{c}\text { Density } \rho \\
\left(\mathrm{g} / \mathrm{cm}^{3)}\right.\end{array}$ & $\begin{array}{c}\text { Volume } v \\
\left(\mathrm{~cm}^{3}\right)\end{array}$ & $\begin{array}{c}\text { Water content } \\
M_{\mathrm{ad}}(\%)\end{array}$ & $\begin{array}{c}\text { Ash content } \\
A_{\mathrm{ad}}(\%)\end{array}$ & $\begin{array}{c}\text { Volatiles } \\
V_{\text {daf }}(\%)\end{array}$ & $\begin{array}{c}\text { Carbon content } \\
F_{\text {cad }}(\%)\end{array}$ \\
\hline JLS & 42.53 & 43.57 & 1.48 & 29.439 & 4.69 & 9.91 & 6.38 & 83.615 \\
ZG1 & 39.7 & 41.16 & 1.42 & 28.986 & 1.665 & 16.51 & 7.37 & 77.075 \\
ZG2 & 37.57 & 38.82 & 1.45 & 26.772 & 2.5 & 7.415 & 7.11 & 85.83 \\
WTP & 43.97 & 45.79 & 1.69 & 27.095 & 1.805 & 15.5 & 6.095 & 79.085 \\
\hline
\end{tabular}

$$
K=\left(\frac{\phi}{C}\right)^{4} \times\left(\frac{\mathrm{FFI}}{\mathrm{BVI}}\right)^{2}
$$

where $\phi$ means porosity and $C$ is coefficient and is an empirical parameter that varies with the samples. FFI is the free fluid index and BVI is the bound fluid index.

\section{Experimental Contents}

3.1. Coal Samples and Parameters Test. Coal samples were collected from No. 1 coal mine in Zhaogu (ZG1), No. 2 coal mine in Zhaogu (ZG2), Jiulishan Mine (JLS), in Jiaozuo Coal Group, and Wangtaipu Mine (WTP) in Jincheng Coal Group. According to the laboratory and field test standardization committee of International Society for Rock Mechanics (ISRM) and to meet the condition of the nuclear magnetic test equipment (the diameter $25 \mathrm{~mm}$ of NMR test coil), the specifications of coal samples were $\Phi 25 \mathrm{~mm} \times 50 \mathrm{~mm}$. Through the parameter test instrument, the industrial analysis results of coal samples are obtained and shown in Table 1.

3.2. Preparation for the Experiment. The instruments used for this experiment included the Meso MR23-060H-I lowfield NMR made by Shanghai Niumag Company. Resonance frequency was $21.67568 \mathrm{MHz}$. Magnet temperature was controlled at $31.99^{\circ} \mathrm{C}$ to $32.01^{\circ} \mathrm{C}$. Magnetic field intensity was $0.5 \mathrm{~T}$, and radiofrequency pulse was 21.67568 MHz. $T_{2}$ spectrum of samples was tested by lowfield NMR instrument. The test parameters of CPMG sequence of coal rock samples were $S W=333.333 \mathrm{KHz}$, $\mathrm{TE}=0.406 \mathrm{~ms}, \mathrm{NS}=32, \mathrm{TW}=3000 \mathrm{~ms}, \mathrm{NECH}=10000$, $\mathrm{RG} 1=15 \mathrm{db}, \quad \mathrm{DRG} 1=3, \quad \mathrm{DR}=1, \quad$ and $\quad \mathrm{PRG}=0, \quad$ and $T_{2 \text { cutoff }}=4 \mathrm{~ms}$ and an empirical value $[24,25]$. The water saturation of coal samples was accomplished by the vacuum saturation equipment, and coal samples were dried in a vacuum drying oven.

3.3. Experiment Steps. Coal samples were denoted as ZG1-1, ZG2-1, JLS-1, and WTP-1 which were used for the lowtemperature experiment, and ZG1-2, ZG2-2, JLS-2, and WTP-2 were used for high-temperature experiment.

In the high-temperature treatment, coal samples (ZG1-2, ZG2-2, JLS-2, and WTP-2) were placed in a drying oven $\left(100^{\circ} \mathrm{C}\right)$ for $5 \mathrm{~h}$. In the low-temperature treatment, coal samples (ZG1-1, ZG2-1, JLS-1, and WTP-1) were placed in a drying oven $\left(30^{\circ} \mathrm{C}\right)$ for the first $1 \mathrm{~h}$, and they were then returned to room temperature and then immersed in liquid nitrogen for $5 \mathrm{~h}$.

Low-field NMR experiments of coal samples were performed before and after the treatment.

(1) Experiment instruments: the instrument is opened and calibrated. Porosity was indicated by a marked line.

(2) Main steps: coal samples were dried for $12 \mathrm{~h}$ in an electro thermal blowing dry box, followed by $12 \mathrm{~h}$ of water saturation in a vacuum-saturated device and 24-h immersion in water until the mass of coal samples remained constant. Coal samples reached the state of water saturation. Finally, the coal samples were enveloped by a preservative film and then placed in the experiment table to test their $T_{2}$ distribution, porosity, permeability, and pore diameter distribution.

\section{Results and Discussion}

\subsection{Effects of Temperature on $T_{2}$ Distribution}

4.1.1. Experimental Results. Test results of $T_{2}$ spectra of all coal samples under different temperatures are shown in Figures 1 and 2 .

4.1.2. Result Analysis. Figure 1 shows that wave peaks in the $T_{2}$ spectra of ZG1-1, ZG2-1, JLS-1, and WTP-1 expand, especially the first one. This finding shows that low temperature significantly influences the porosity of high-rank coals. The area of all $T_{2}$ spectra increases to some extent, which indicates that pore and fracture volume in coal samples increase, which are processed under lowtemperature treatment. Figure 2 shows that the peak values of all $T_{2}$ spectra of ZG1-2, ZG2-2, JLS-2, and WTP-2 decrease, which is also manifested by changes of the first wave peak. Therefore, high temperature can significantly affect the porosity of high-rank coals. The narrowing $T_{2}$ spectral area reflects the reduction of pore and fracture volume in coal samples after high-temperature treatment. This finding is attributed to thermal expansion and cold contraction of the coal matrix. The cold contraction of the coal matrix under low temperature increases pore and fracture volume. By contrast, expansion under high temperature squeezes the original pores, thereby reducing pore and fracture volume. 


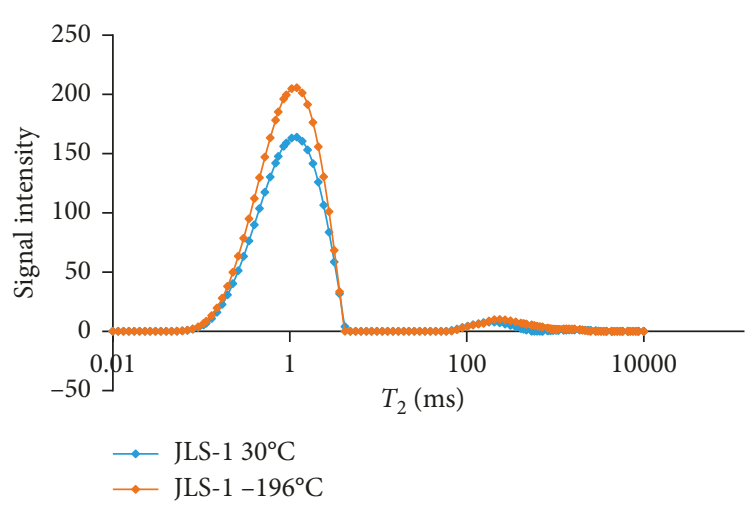

(a)

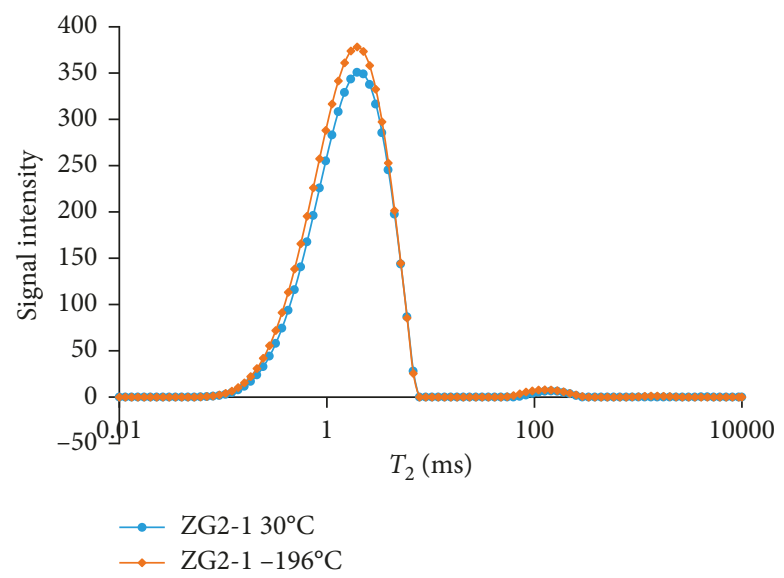

(c)

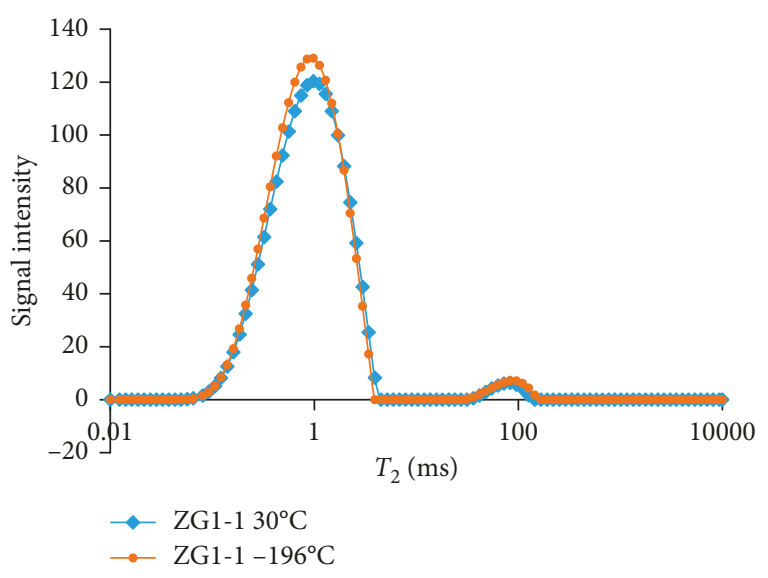

(b)

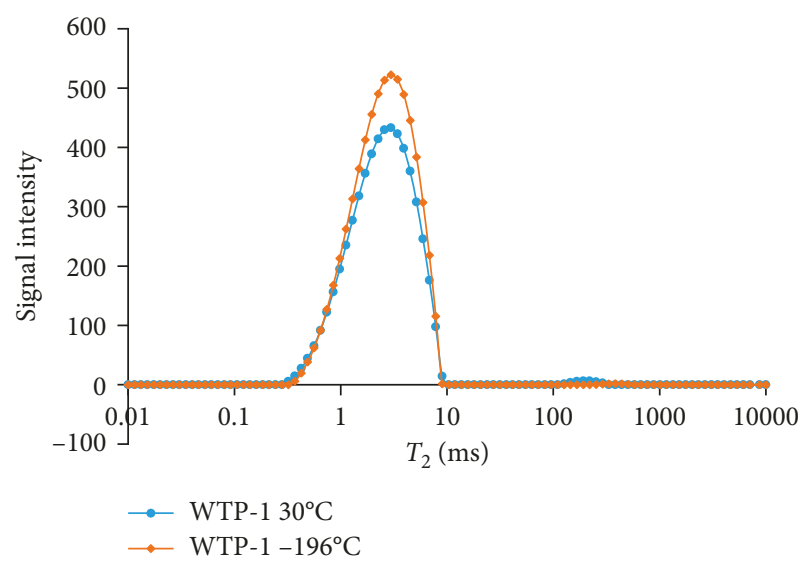

(d)

Figure 1: $T_{2}$ spectra of coal samples under low-temperature conditions.

\subsection{Effects of Temperature on the Porosity and Permeability of Coal Samples}

4.2.1. Experimental Results. The test results of $T_{2}$ spectra of all coal samples under different temperatures are shown in Tables 2 and 3.

4.2.2. Result Analysis. Table 2 shows that the porosity and permeability of JLS-1, ZG1-1, ZG2-1, and WTP-1 all increase to some extent. The growth amplitudes of porosity are $3.8 \%, 6.8 \%, 5.1 \%$, and $5 \%$, whereas the growth amplitudes of permeability are $32.7 \%, 29.5 \%, 34 \%$, and $35.6 \%$. Table 3 shows that the porosity and permeability of JLS-2, ZG1-2, ZG2-2, and WTP-2 decline. The former decreases by $-10.5 \%$, $-13.6 \%,-7.9 \%$, and $-11.2 \%$, whereas the latter one decreases by $-42.2 \%,-28.1 \%,-30.3 \%$, and $-31.9 \%$, respectively. The growth/reduction amplitudes of permeability are always higher than those of porosity. The analysis shows that high temperature can decrease the porosity and permeability of coal samples, whereas low temperature can increase these two parameters. Porosity is less sensitive to temperature compared with permeability because temperature influences pores, and fractures of coal samples can be easily closed or expanded but they cannot be easily recovered. Permeability differs from porosity. The throat structure is located opposite to the pore structure and shows a buttress.

\subsection{Effects of Temperature on Pore Diameter Distribution in Coal Samples}

4.3.1. Experimental Results. The test results of $T_{2}$ spectra of all coal samples under different temperatures are shown in Figures 3 and 4.

4.3.2. Results Analysis. Figures 3 and 4 show that the distribution of pore diameter changes after low-temperature and high-temperature treatments.

From Figure 3, it can be seen that after low-temperature treatments, the proportion of microspores $(0-10 \mathrm{~nm}) \mathrm{de}$ creases, the proportion of small pores $(10-100 \mathrm{~nm})$ increases, the proportion of mesopores remains the same, and the proportion of macrospores increases to some extent. The reason to this phenomenon is when the liquid nitrogen contacts with the coal and cools it with temperature of $-196^{\circ} \mathrm{C}$, it can produce a shrinkage stress about 


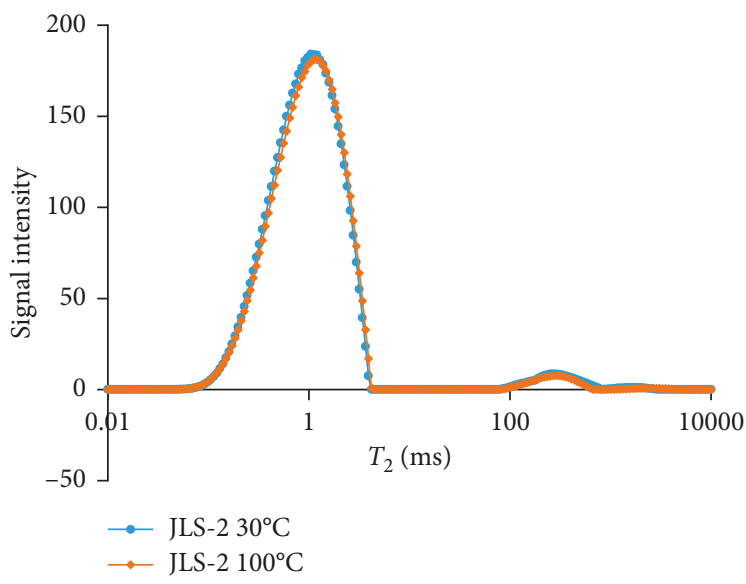

(a)

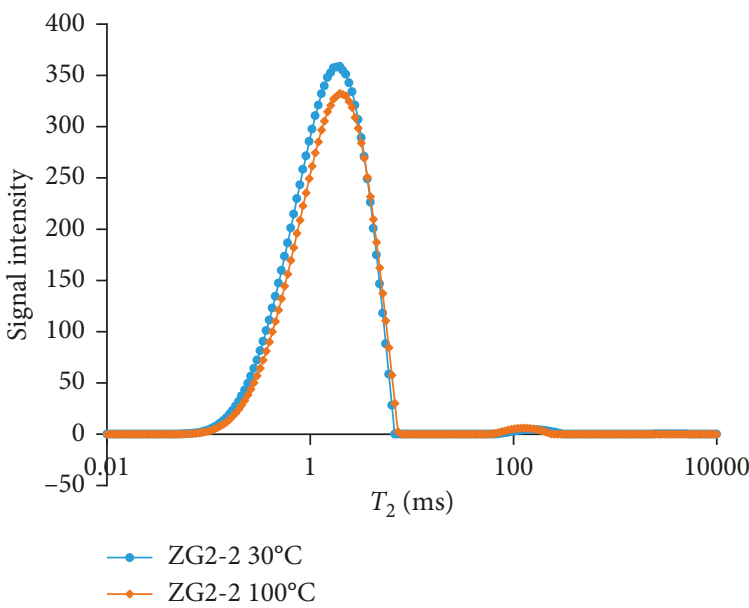

(c)

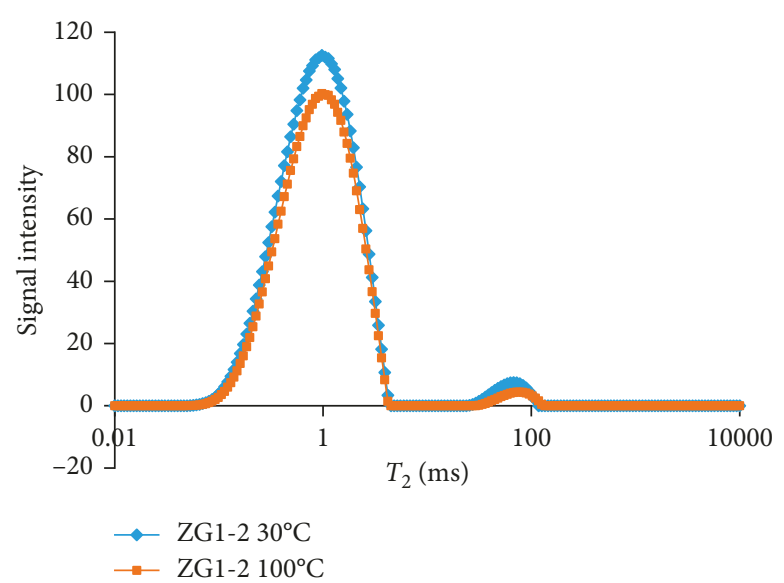

(b)

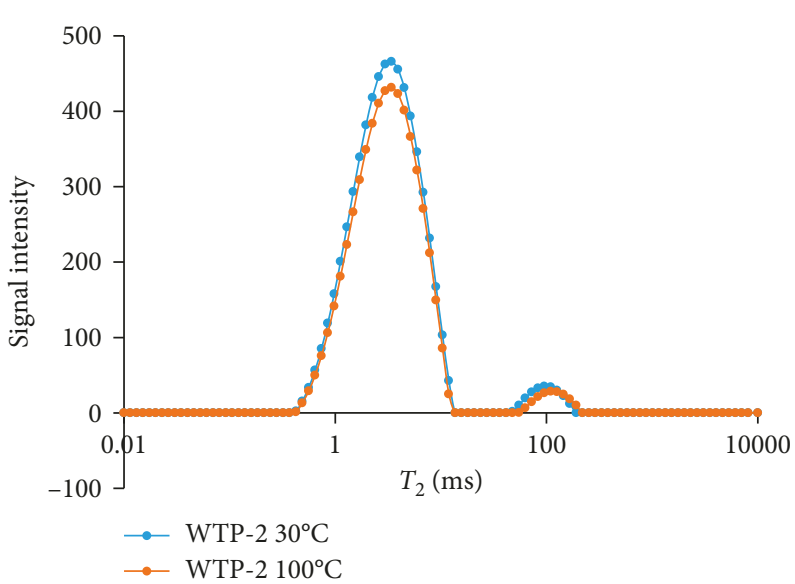

(d)

Figure 2: $T_{2}$ spectra of coal samples under high-temperature conditions.

Table 2: Porosity and permeability of coal samples under low temperature.

\begin{tabular}{|c|c|c|c|c|c|}
\hline \multirow{2}{*}{ Number } & \multicolumn{5}{|c|}{ Project } \\
\hline & Temperature $\left({ }^{\circ} \mathrm{C}\right)$ & Porosity & Increase rate $(\%)$ & Permeability $\left(10^{-4} \cdot \mathrm{mD}\right)$ & Increase rate $(\%)$ \\
\hline JLS-1 & 30 & 2.959 & & 0.087 & \\
\hline JLS-1 & -196 & 3.107 & 5 & 0.118 & 35.6 \\
\hline ZG1-1 & 30 & 6.457 & & 2.688 & \\
\hline ZG1-1 & -196 & 6.7 & 3.8 & 3.568 & 32.7 \\
\hline ZG2-1 & 30 & 7.228 & & 40.078 & \\
\hline ZG2-1 & -196 & 7.721 & 6.8 & 51.916 & 29.5 \\
\hline WTP-1 & 30 & 8.976 & & 623.459 & \\
\hline WTP-1 & -196 & 9.438 & 5.1 & 835.536 & 34 \\
\hline
\end{tabular}

$27 \mathrm{MPa}$, which is more than the compressive strength of coal. The stress damages the coal's inner structure and increases the total porosity of coal. Also, due to the shrinkage stress impacts, it increases the radius of the pores and the width of macrospores. All these caused some micropores into small pores and increased the proportion of macrospores.

From Figure 4, it can be seen that after high-temperature treatments, the proportion of microspores increases, the proportion of small pores decreases, and the proportion of macrospores decreases to some extent. As the anthracite coal undergoes high temperature or magmatic erosion during the coalification process, it can resist high temperature and has a higher tensile strength. With the treatments of high temperature on coal, the coal rock matrix is expanded, the space of the original fracture is squeezed, and the porosity is reduced. All these effects make the porosity decrease, the ratio of pore to total porosity increases, the proportion of 
TABle 3: Porosity and permeability of coal samples under high temperature.

\begin{tabular}{lccccc}
\hline Number & & \multicolumn{2}{c}{ Project } & & \\
& Temperature $\left({ }^{\circ} \mathrm{C}\right)$ & Porosity & Increase rate $(\%)$ & Permeability $\left(10^{-4} \cdot \mathrm{mD}\right)$ & Increase rate $(\%)$ \\
\hline JLS-2 & 30 & 3.178 & -11.2 & 0.072 & -31.9 \\
JLS-2 & 100 & 2.821 & & 2.824 & -1.632 \\
ZG1-2 & 30 & 6.679 & -10.5 & 41.71 & -42.2 \\
ZG1-2 & 100 & 5.981 & -13.6 & 29.991 & -28.1 \\
ZG2-2 & 30 & 7.387 & & 743.256 & -30.3 \\
ZG2-2 & 100 & 6.382 & -7.9 & 518.364 & \\
WTP-2 & 30 & 10.743 & & & \\
WTP-2 & 100 & 9.89 & & & \\
\hline
\end{tabular}

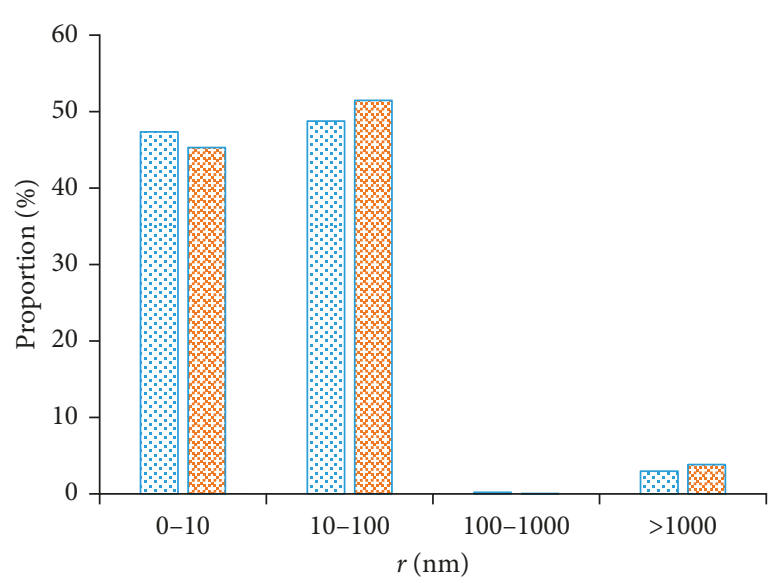

JLS- $130^{\circ} \mathrm{C}$

图 JLS- $1-196^{\circ} \mathrm{C}$

(a)

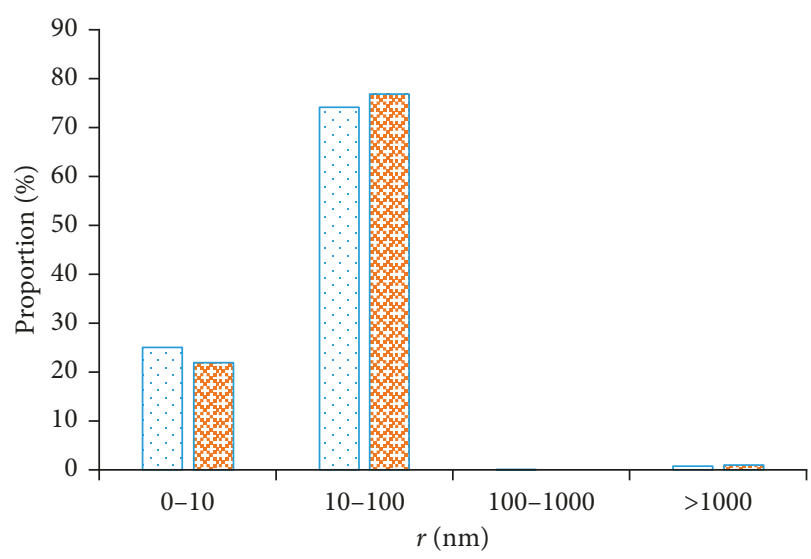

$\square \mathrm{ZG} 2-130^{\circ} \mathrm{C}$

图 ZG2-1 $-196^{\circ} \mathrm{C}$

(c)

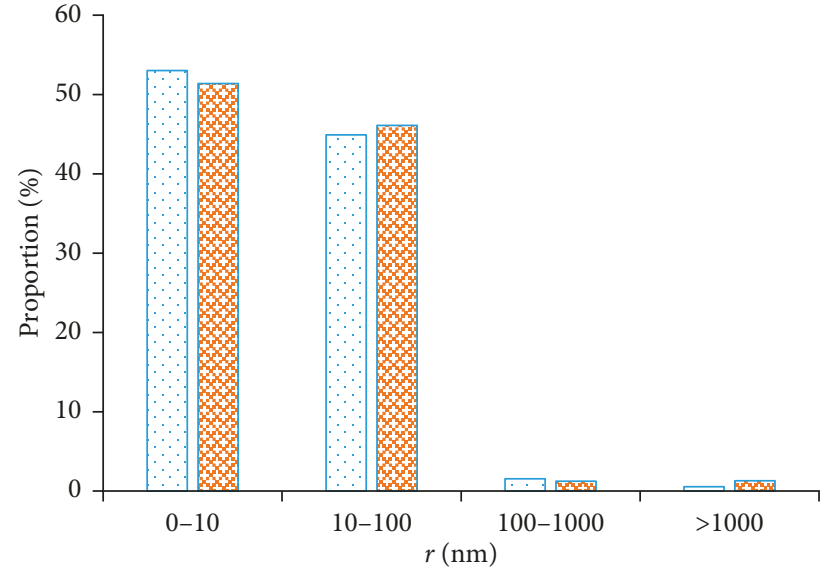

[. ZG1-1 $30^{\circ} \mathrm{C}$

图 ZG1-1-196 ${ }^{\circ} \mathrm{C}$

(b)

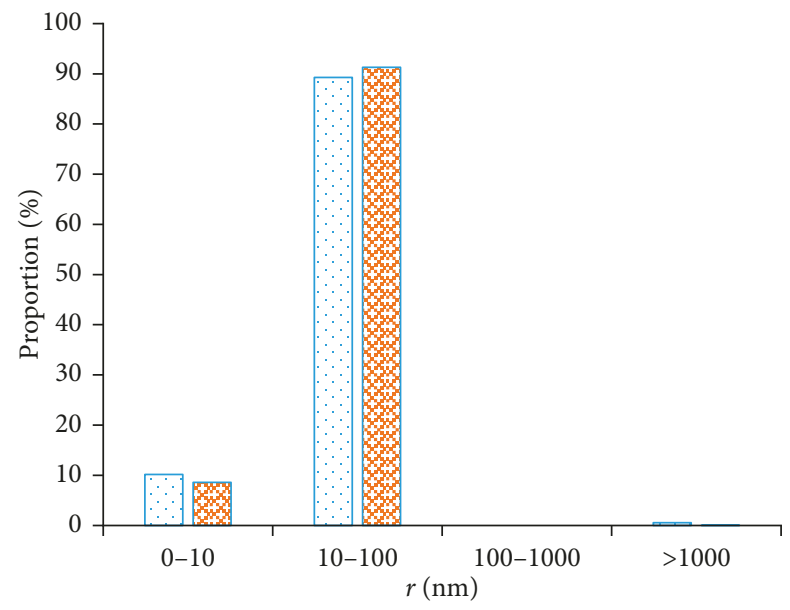

. WTP $-130^{\circ} \mathrm{C}$

圆 WTP- $1-196^{\circ} \mathrm{C}$

(d)

Figure 3: Histogram of pore size distribution of coal samples under low temperature.

small pore decreases, and the proportion of large pores has been reduced. Similarly, the reduction of porosity and permeability of JLS-2, ZG1-2, ZG2-2, and WTP-2 is the consequence of proportion reduction of small pores and macrospores under high temperature.

\section{Conclusions}

(1) Peak value, spectral area, pore volume, porosity, and permeability increase in the $T_{2}$ spectra of coal samples after low-temperature treatment. The proportion of 


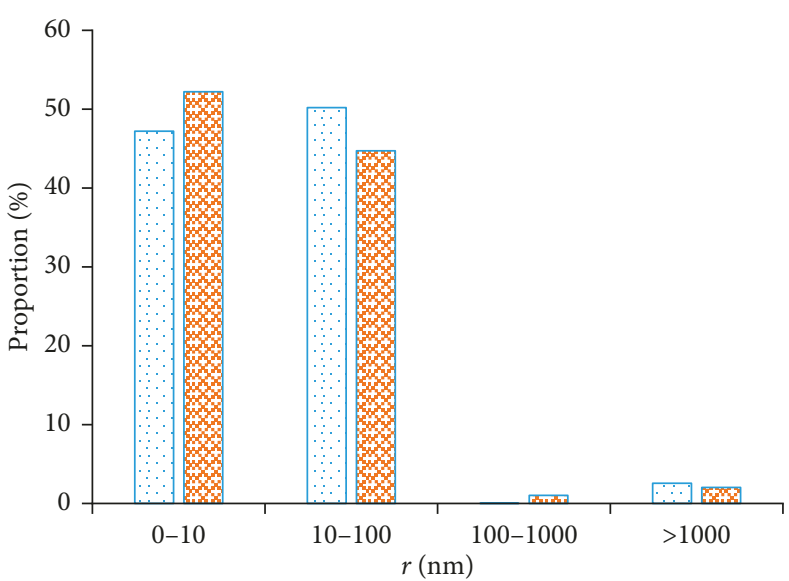

JLS- $230^{\circ} \mathrm{C}$

因 JLS- $2100^{\circ} \mathrm{C}$

(a)

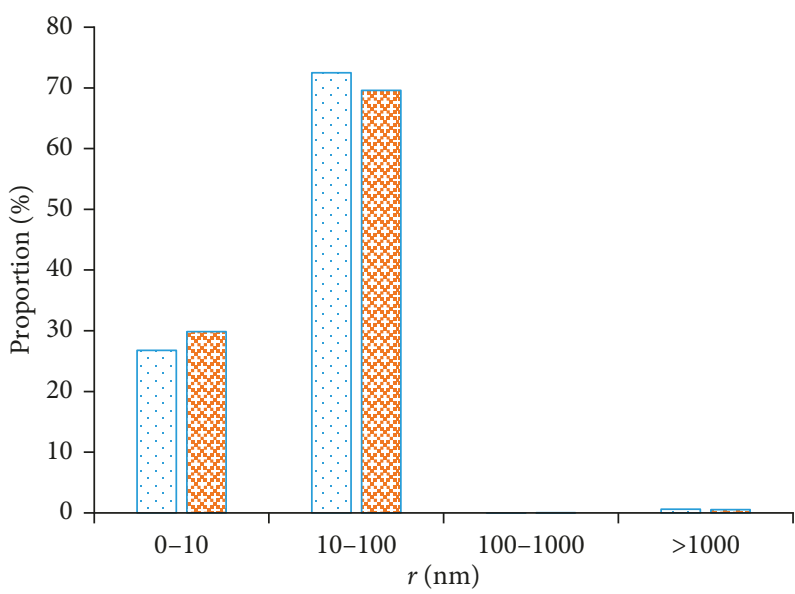

ZG2-2 $30^{\circ} \mathrm{C}$

Z $\mathrm{ZG} 2-2100^{\circ} \mathrm{C}$

(c)

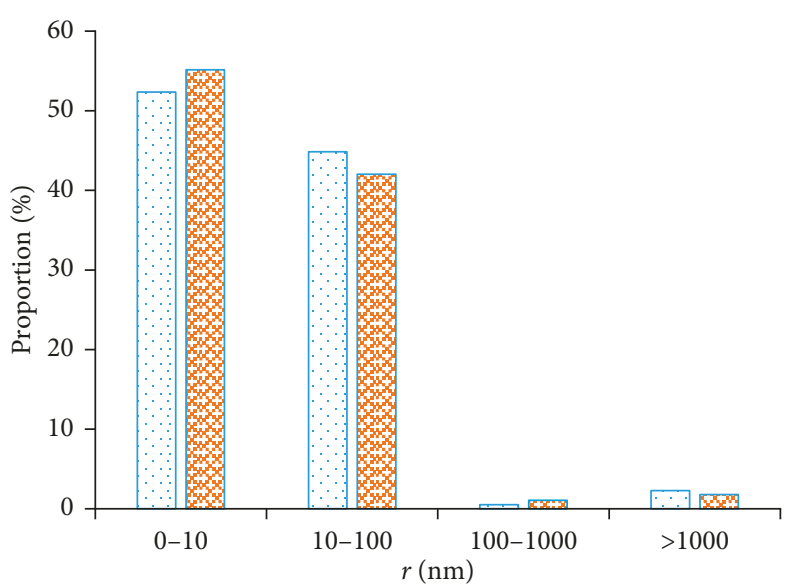

Z ZG1-2 $30^{\circ} \mathrm{C}$

ZG1-2 $100^{\circ} \mathrm{C}$

(b)

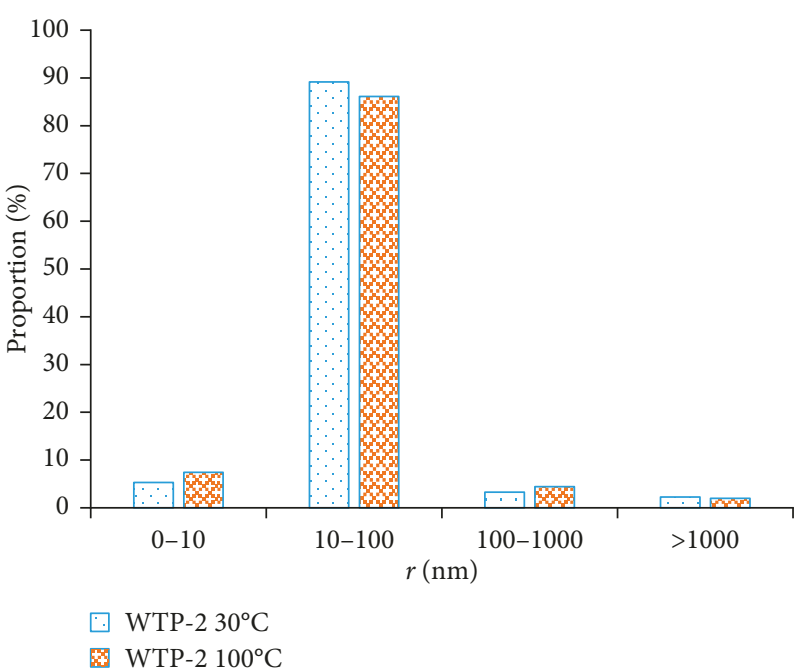

(d)

Figure 4: Histogram of pore size distribution of coal samples under high-temperature conditions.

microspores decreases, the proportion of small pores increases, and the proportion of mesopores remains the same, and the proportion of macrospores increases to some extent. The peak value, spectral area, pore volume, porosity, and permeability decrease in the $T_{2}$ spectra of coal samples after high-temperature treatment. The proportion of microspores increases, the proportion of small pores decreases, the proportion of mesopores remains the same, and the proportion of macrospores decreases to some extent. Permeability is significantly more sensitive to temperature stress than porosity.

(2) Based on the experiment of coal samples after ultrahigh and ultralow temperature treatment, the peak values on the $T_{2}$ spectra of all coal samples increase gradually with the reduction of temperature. This result is accompanied with growths of spectra area, pore and fracture volume, porosity, and permeability. Accordingly, the proportion of microspores decreases, the proportion of small pores increases, the proportion of mesopores remains the same, and the proportion of macrospores increases to some extent.

\section{Data Availability}

All the original data used to support the findings of this study are shown in the figures.

\section{Conflicts of Interest}

The authors declare that they have no conflicts of interest.

\section{Acknowledgments}

This work was supported by the National Nature Science Foundation of China (51734007, 51704099, and 51604101), 
Program for Innovative Research Team in University of Ministry of Education of China (IRT_16R22), Henan Province University Science and Technology Innovation Team (17IRTSTHN030), and the Doctoral Fund of Henan Polytechnic University (B2015-09). The authors are grateful for their support.

\section{References}

[1] Y. Qi, "High rank coal gas and admissibility of influencing factors," Science and Technology \& Innovation, vol. 9, pp. 120-121, 2015.

[2] Z. H. Chen, Y. B. Wang, K. Guo, Q. P. Sun, and Y. P. Zhang, "Stress sensitivity of high-rank coalbed methane reservoir," Acta Geologica Sinica, vol. 10, pp. 1390-1395, 2008.

[3] Z. P. Meng and Q. L. Hou, "Experimental research on stress sensitivity of coal reservoir and its influencing factors," Journal of China Coal Society, vol. 3, pp. 430-437, 2012.

[4] Y. Zhang, Study on Gas Production Mechanism and Discipline of High Rank Coalbed Methane in Southern of Qinshui Basin, Chongqing University, Chongqing, China, 2009.

[5] G. Wu, A. G. Xing, and L. Zhang, "Mechanical characteristics of sandstone after high temperatures," Chinese Journal of Rock Mechanics and Engineering, vol. 26, pp. 2110-2116, 2007.

[6] G. Wu, Y. N. Teng, and Y. Wang, "Physical and mechanical characteristics of limestone after high temperature," Chinese Journal of Rock Mechanics and Engineering, vol. 33, pp. 259-264, 2011.

[7] Y. P. Qiu and Z. Y. Lin, "Testing study on damage of granite samples after high temperature," Rock and Soil Mechanics, vol. 27, pp. 1005-1010, 2006.

[8] G. S. Yang, "A review on frozen rock mechanics," Mechanics in Engineering, vol. 31, pp. 9-16, 2009.

[9] G. S. Yang, J. M. Xi, H. J. Li, and L. Cheng, "Experimental study of rock mechanicall properties under triaxial compressive and frozen conditions," Chinese Journal of Rock Mechanics and Engineering, vol. 29, pp. 459-464, 2010.

[10] Z. H. Feng, Y. S. Zhang, Z. J. Wan, G. W. Li, C. Wang, and Y. Zhang, "Law of permeability in the process of anthracite deformation with thermo-mechanical coupling," Journal of China Coal Society, vol. 35, pp. 86-90, 2010.

[11] Y. Q. Hu, Y. S. Zhao, D. Yang, and Z. Q. Kang, "Experimental study of effect of temperature on permeability characteristics of lignite," Chinese Journal of Rock Mechanics and Engineering, vol. 29, pp. 1585-1590, 2010.

[12] M. M. Li, The Research on Pyrolysis-Penteration and Microstructure of Lignite, Taiyuan University of Technology, Taiyuan, China, 2012.

[13] X. L. Yang and Y. L. Zhang, "Experimental study of effect of temperature on coal gas permeability under gas-solid coupling," Journal of Geomechanics, vol. 14, pp. 374-380, 2008.

[14] Y. Zhang, "The history of nuclear magnetic resonance technology and its application," Science \& Technology Information, vol. 15, pp. 116-118, 2010.

[15] Y. D. He, Z. Q. Mao, L. Z. Xiao, and X. J. Ran, “An improved method of using NMR T2 distribution to evaluate pore size distribution," Chinese Journal of Geophysics, vol. 2, pp. 37378, 2005.

[16] X. X. Sun, Y. B. Yao, J. Y. Chen, S. B. Xie, and C. C. Li, "Determination of coal wettability by using low-field nuclear magnetic resonance," Geoscience, vol. 1, pp. 190-197, 2015.

[17] G. R. Coates, L. Z. Xiao, and M. G. Prammer, NMR Logging Principles and Applications, Gulf Professional Publishing, Houston, TX, USA, 1993.
[18] L. Z. Xiao, "Recent development on nuclear magnetic resonance in rock samples and its appellations," Well Logging Technology, vol. 1, pp. 27-31, 1996.

[19] Q. Shi and Y. S. Pan, "A method of nuclear magnetic resonance imaging analyzed in the crack and fluid pass way of coal body," Coal Mining Technology, vol. 6, pp. 10-13, 2005.

[20] S. B. Xie, Y. B. Yao, J. Y. Chen, and W. Yao, "Research of micro-pore structure in coal reservoir using low-field NMR," Journal of China Coal Society, vol. S1, pp. 170-176, 2015.

[21] F. Xiao, The Application Study of NMR Logging-The Study of Clastic Rock Reservoir Pore Structure, T2 Dynamic Cutoff Value, Heavy Oil Identification, Yangtze University, Jingzhou, China, 2012.

[22] H. L. Zhu, K. P. Zhou, Y. M. Zhang, K. Tian, and J. L. Li, "Experimental study of rock damage by blasting based on nuclear magnetic resonance technique," Chinese Journal of Rock Mechanics and Engineering, vol. 7, pp. 1410-1416, 2013.

[23] Q. S. Huang, W. J. Zhao, J. Q. Yang, and B. K. Liu, "Research and application of NMR permeability models," Journal of Qingdao University, vol. 4, pp. 37-40, 2004.

[24] L. Xiao and Z. X. Xiao, "Analysis of methods for determining NMR $\mathrm{T}_{2 \text { cutoff }}$ and its applicability," Progress in Geophysics, vol. 1, pp. 167-172, 2008.

[25] J. Lin, T. Ren, G. Wang, P. Booth, and J. Nemcik, "Experimental investigation of $\mathrm{N}_{2}$ injection to enhance gas drainage in $\mathrm{CO}_{2}$-rich low permeable seam," Fuel, vol. 215, pp. 665-674, 2018. 


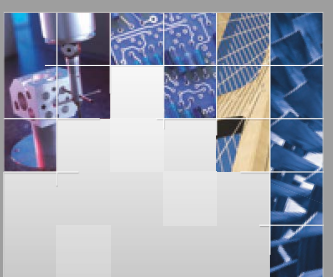

\section{Enfincering}
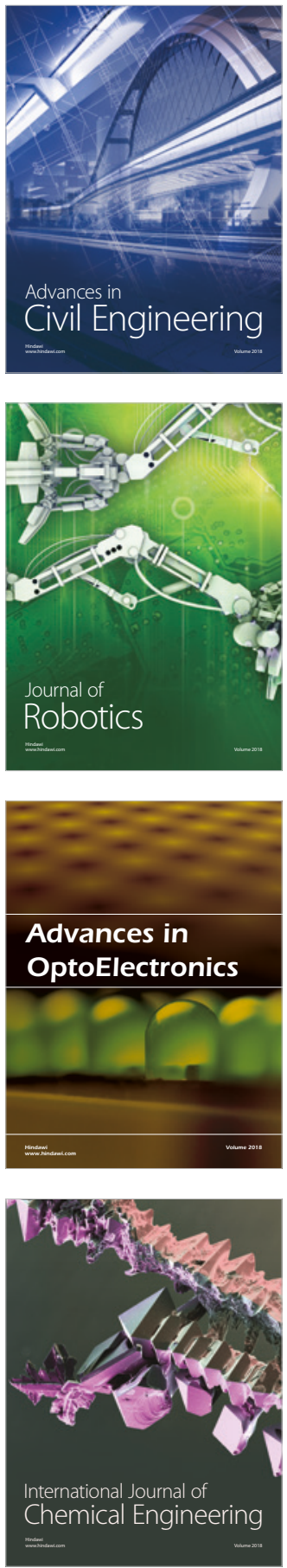

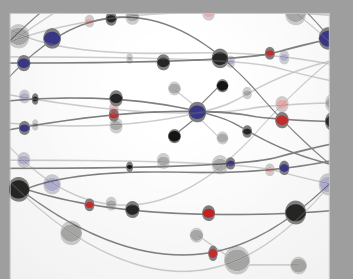

\section{Rotating \\ Machinery}

The Scientific World Journal

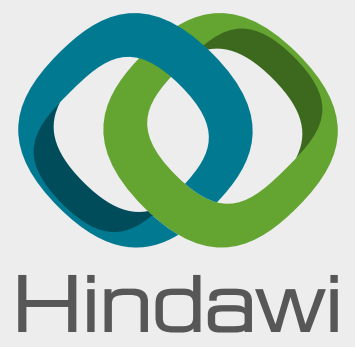

Submit your manuscripts at

www.hindawi.com
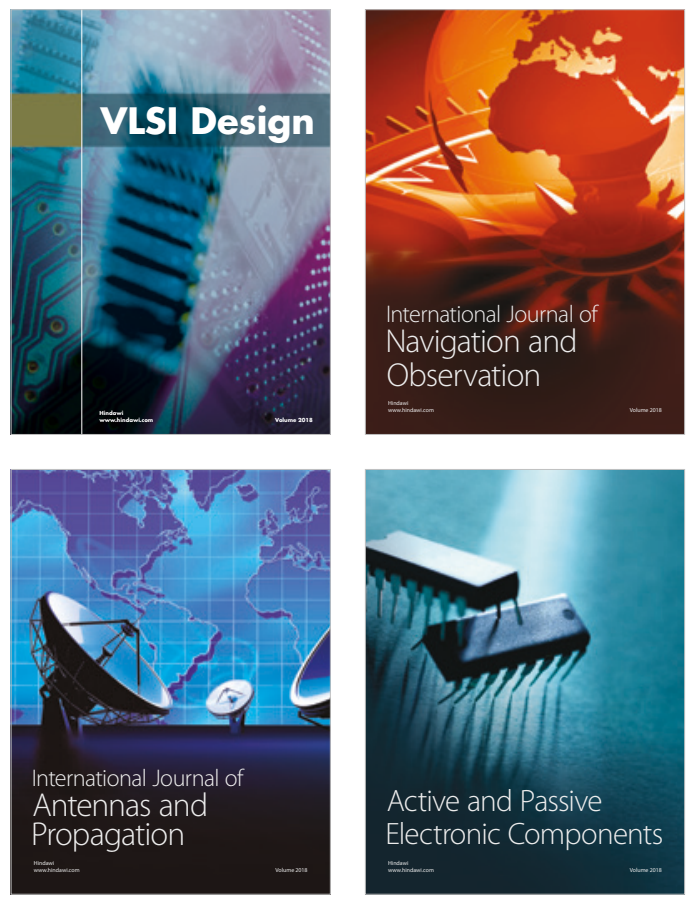
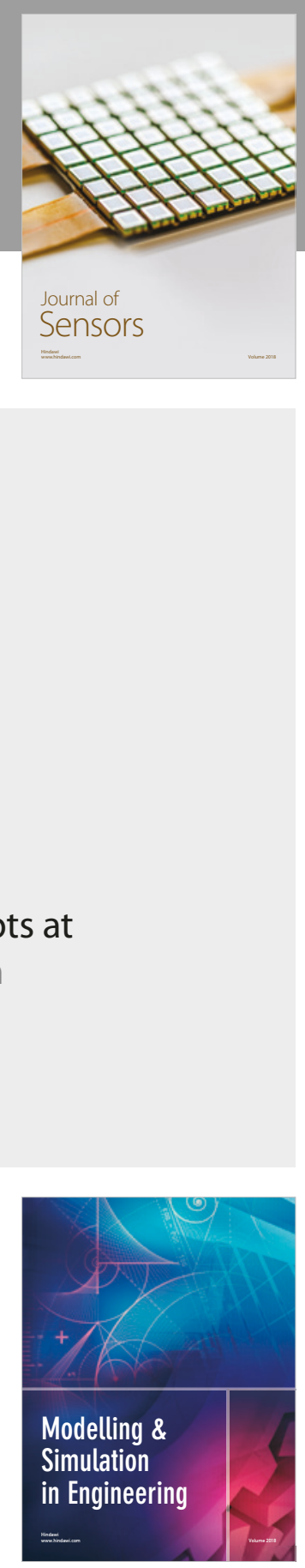

\section{Advances \\ Multimedia}
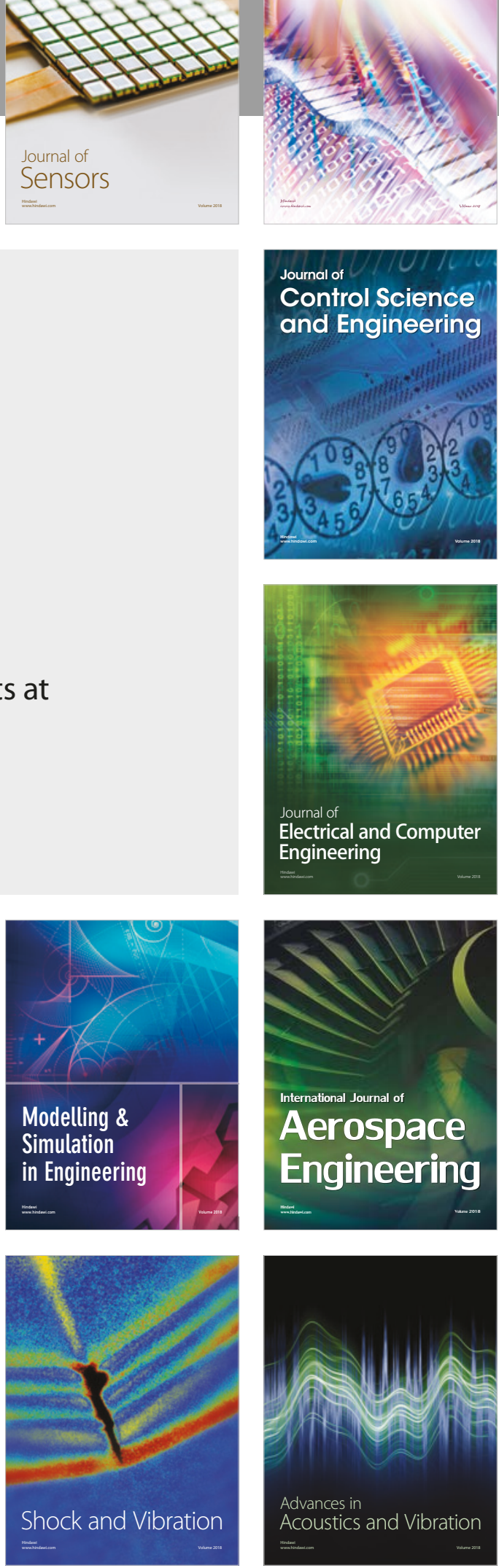